\title{
45 Vestibular labyrinthine physiology
}

A The utricular macula responds to angular acceleration.

B Bithermal caloric responses are abolished in conditions of zero gravity.

C Ampullofugal displacement of the cupula of the superior semicircular canal increases vestibular nerve activity.

D The saccular maculae lie in a horizontal plane.

$\mathrm{E}$ Steady rotation is detected by the semicircular canals.

\section{Vestibular function tests}

A In the bithermal caloric test the ears are irrigated for $40 \mathrm{~s}$ with water, $5^{\circ}$ Celsius above and below normal body temperature.

$B$ Rotation to the left indicates a labyrinthine disorder on the ipsilateral side during Unterberger's test.

C In gait tests the subject tends to deviate to the affected side.

D An abnormal optokinetic nystagmus usually indicates a central vestibular problem.

E Doll's head eye movements are lost with lesions of the basal ganglia.

\section{Bithermal caloric test}

A The fixation index compares the duration of nystagmus with and without optic fixation.

$B$ Decreased responses always indicate pathology.

C Enhanced responses may be seen in cerebellar lesions.

D Frenzel's glasses abolish optic fixation.

E Water is introduced into the ear using a Dundas Grant coiled copper tube. 